\title{
A snap-shot of organisational provisions for Māori children and youth with special needs
}

\author{
Jill Bevan-Brown \\ Department of Learning and Teaching, Massey University
}

\begin{abstract}
This article presents the findings of a survey to gather information about the scope, prevalence and effectiveness of programmes and services for Māori children and youth with special needs. Analysis of relevant organisational documentation including a postal survey completed by 78 people from 56 different special educational, Māori, support and disability organisations, and 25 follow-up interviews, revealed that a wide range of services and programmes were being offered by organisations throughout Aotearoa/ New Zealand. Out of the organisations surveyed fifty-eight percent were providing programmes and services especially developed or adapted for Māori, and forty-one percent had a person with particular responsibility for or expertise in this area. Common components of effective programmes and services were: the incorporation of cultural content; the involvement of parents, whānau, the Māori community, Māori organisations and Māori workers; and ready accessibility. Respondents described 56 different effective strategies and 39 challenges to providing for Māori children and youth with special needs. The five major barriers identified were: insufficient funding; lack of culturally appropriate resources and people with cultural and professional expertise; a shortage of culturally appropriate, relevant training; Pākehā-centric attitudes towards special needs provisions; and high stress levels of Māori staff working in the special needs domain.
\end{abstract}

\section{KEYWORDS:}

Māori, Māori culture, special needs, special education, culturally appropriate strategies, family involvement, effective practices.

\section{INTRODUCTION}

Māori learners with special needs are entitled to culturally appropriate and effective programmes and services. This entitlement is contained in a wide range of legislation and official documentation. ' However, despite this commitment on paper, there is considerable research to show that Māori learners with special needs are not being adequately provided for. The literature reveals that this includes:

- a shortage of culturally appropriate special education services, such as a lack of Māori content in programmes

- a dearth of Māori-relevant resources and assessment measures

For an outline of this legislation and official documentation, see BevanBrown (2002, p.2)
- a scarcity of culturally appropriate implementation and delivery processes

- a shortage of programmes, services, resources and assessment measures in te reo Māori with a consequential low referral rate from kohanga reo and kura kaupapa Māori

- a failure to recognise and provide for Māori perceptions of special needs

- a low number of Māori amongst special education personnel

- a lack of support for Māori staff working in the special education domain

- a shortage of special education professionals with the cultural knowledge needed to work with Māori learners

- a lack of recognition of the importance of culturally appropriate services amongst principals, teachers, teacher aides and special education professionals

- a shortage of special education expertise and knowledge of SE2000 initiatives amongst teachers in Māori immersion facilities

- a lack of professional development specifically targeted for kaiako and kaiāwhina in total immersion education

- parental difficulties in finding and accessing appropriate help.

(Bevan-Brown \& Bevan-Brown, 1999; Cullen \& Bevan-Brown, 1999; Duckworth, 1999; Massey University Research Team, 1999, 2001, 2002; Ministry of Health, 2001; Peretini et al., 2000; Schwarz \& Gillon, 1999; Wilkie, 1999, 2001; Wylie, 2000).

My PhD was motivated by a desire to address some of the concerns identified in these research findings. It involved a six-year study that sought to find out how Māori learners with special needs could have their needs met in a culturally appropriate and effective way, to identify challenges to achieving this and to devise ways these challenges could be overcome. A multi-method approach was used. This included a review of the Aotearoa/New Zealand and international literature; an organisation survey; interviews with parents, whānau and Māori learners with special needs; a longitudinal case study of one particular learner; focus group meetings of whānau from six kohanga reo and the development and trialing of a cultural self-review. This article reports the findings from the organisation survey. 


\section{METHOD}

The organisation survey conducted in the initial phase of my PhD was an exploratory tool. Its aims were to:

1. Ascertain the scope and prevalence of services and programmes specifically developed or adapted for Māori learners with special needs.

2. Identify successful services and programmes offered to Māori children and youth with special needs.

3. Identify challenges organisations face in providing for Māori learners with special needs.

The organisation survey contained three components: Postal Survey

A Postal Survey with seven questions relating to the provision, nature and extent of services offered to Māori learners with special needs was posted to 105 different special education providers, support services, Māori and disability organisations. These were selected from a list of agencies supplied by the Palmerston North Disabilities Resource Centre and from TAKOA 1996, (Te aka kumara o Aotearoa: Directory of Māori organisations and resource people in Aotearoa). The sample included all major special education and disability services in Aotearoa/New Zealand and also relevant support and Māori organisations. As a result of feedback from this mail-out and from personal contacts, 44 more questionnaires were sent. This second mail-out was mainly to people at the local branch level of national organisations. Feedback was received from 78 people representing 56 different organisations. Allowing for "address unknown" returns, the overall response rate for the survey was fifty-three percent.

\section{Semi-structured interviews}

Twenty-five follow-up interviews were conducted with contacts from the postal survey - seventeen were by telephone and eight were face-to-face. They were based on the written questionnaire but extended beyond that to include in-depth discussion of points raised by the participants.

\section{Documentary analysis}

A request for relevant "brochures, pamphlets, booklets, policy statements etc." was included in the written questionnaire. Twenty-seven organisations responded to this request. Further documentation was collected at relevant hui and seminars.

\section{DATA ANALYSIS}

Data gathered from all sources were combined and both qualitative and quantitative strategies were used in analysis. Qualitative analysis strategies were used on data relating to the scope and nature of programmes and services for Māori learners with special needs and to the challenges organisations face in meeting these needs. A quantitative approach was chosen to ascertain the prevalence of services and programmes for Māori learners with special needs. In calculating prevalence figures respondents were divided into four categories.

\section{RESULTS}

\section{Prevalence and scope of services and programmes} The first question of the survey sought information about the existence of services or programmes specifically developed or adapted for Māori learners with special needs while question five inquired about the presence of people with responsibility for or expertise in providing these services and programmes. The answers given are presented in the following tables.

For question five, a variety of arrangements were mentioned. These situations were "official" responsibility delegated to individuals, Māori units or committees within an organisation. Their brief involved providing advice about service content and delivery and acting as advocates and Māori representatives. In other organisations individual Māori workers or whānau groups were regularly consulted but had no "official" responsibility or designation, Māori experts were employed by an organisation's national body to advise and assist local branches when required, or itinerant Māori experts were employed who would work within a specified geographical area.

Six respondents who did not have people with Māori expertise in their own organisation consulted and used local Māori organisations, groups, experts, whānau and iwi as well as national Māori organisations and national experts when the need arose.

A variety of services and programmes in a wide range of areas was described. These included educational, social, recreational, promotional, medical, preventative, support and nurturing, assessment and screening, rehabilitation, liaison, therapeutic, referral, caretaking and accommodation, advisory, translation, advocacy, lobbying, fundraising and financial support, policy development, research and counseling programmes and services.

\section{Successful services and programmes}

An analysis of services and programmes reported as effective with Māori children and youth with special needs revealed 56 different strategies were being utilised. These strategies were grouped into eight categories: participation, partnership, cultural content, personnel, administration, policy, integration, and accessibility and equality. These wide-ranging strategies include:

- the use of whānau networks to identify needs and advertise programmes

- having Māori representatives on Executive Boards

- the development and use of Māori-appropriate resources such as Māori dolls in therapy, talking books about Māori characters and pātere used in asthma breathing exercises

- the establishment of administrative processes for internal or external cultural auditing

- active recruitment and training in Māori communities to provide a pool of community-based, support people

- policy commitment to target services to areas where Māori needs have been identified

- $\quad$ staff from Māori services working alongside Pākehā professionals in mainstream services

- whānau given a choice of service/meeting time and venue. 
TABLE 1

Number and Type of Organisation Surveyed

\begin{tabular}{lccll}
\hline CATEGORY & NO & $\%$ & DESCRIPTION & EXAMPLE \\
\hline Educational & 8 & 11 & $\begin{array}{l}\text { Groups providing educational services } \\
\text { in the special needs area. }\end{array}$ & Group Special Education \\
Māori & 6 & 8 & $\begin{array}{l}\text { Hapū, iwi or pan-Māori groups providing } \\
\text { a range of health, welfare, social, disability } \\
\text { and educational services to Māori. }\end{array}$ & Whānau Ora Services - Te Rūnanga o \\
& 23 & 32 & $\begin{array}{l}\text { Groups providing a particular service to } \\
\text { people with a range of special needs. }\end{array}$ & Riding for the Disabled and \\
Support & 36 & Proups specialising in services to a & IHC and the Cerebral Palsy Assoc. \\
Disability & 49 & particular category of disability. &
\end{tabular}

TABLE 2

Does Your Organisation Provide Specific or Adapted Services or Programmes for Māori Children and Youth With Special Needs?

\begin{tabular}{|c|c|c|c|c|c|c|c|c|}
\hline \multirow[t]{2}{*}{ GROUP } & \multicolumn{2}{|c|}{ YES } & \multicolumn{2}{|c|}{ NO } & \multicolumn{2}{|c|}{ ADAPTED } & \multicolumn{2}{|c|}{ NO ANS/NA } \\
\hline & No. & $\%$ & No. & $\%$ & No. & $\%$ & No. & $\%$ \\
\hline Educational & 5 & 62.5 & 1 & 12.5 & 1 & 12.5 & 1 & 12.5 \\
\hline Māori & 5 & 83 & 0 & 0 & 0 & 0 & 1 & 17 \\
\hline Support & 4 & 17 & 9 & 39 & 8 & 35 & 2 & 9 \\
\hline Disability & 7 & 20 & 14 & 39 & 12 & 33 & 3 & 8 \\
\hline Total & 21 & 29 & 24 & 33 & 21 & 29 & 7 & 9 \\
\hline
\end{tabular}

\section{TABLE 3}

Do You Have Any Person/s in Your Organisation With Particular Responsibility for or Expertise in Providing Services or Programmes for Māori With Special Needs?

\begin{tabular}{|c|c|c|c|c|c|c|}
\hline \multirow[t]{2}{*}{ GROUP } & \multicolumn{2}{|c|}{ YES } & \multicolumn{2}{|c|}{ NO } & \multicolumn{2}{|c|}{ NO ANS/NA } \\
\hline & No. & $\%$ & No. & $\%$ & No. & $\%$ \\
\hline Educational & 7 & 88 & 1 & 12 & 0 & 0 \\
\hline Māori & 5 & 83 & 0 & 0 & 1 & 17 \\
\hline Support & 8 & 35 & 11 & 48 & 4 & 17 \\
\hline Disability & 10 & 28 & 18 & 50 & 8 & 22 \\
\hline Total & 30 & 41 & 30 & 41 & 13 & 18 \\
\hline
\end{tabular}

\section{COMMON COMPONENTS OF SUCCESSFUL PROGRAMMES AND SERVICES}

An analysis of the research data also revealed that successful programmes and services contained a number of common components.

The incorporation of cultural content including Māori knowledge, skills, experiences, processes, language, tikanga, values and beliefs

Having a special need was not viewed as negating an individual's culture. On the contrary, culture was considered to be a vital part of a person's being and an asset to be nourished and drawn on in any intervention. The inclusion of cultural content in programmes and services demonstrated a commitment to and valuing of taha Māori. It was evidenced in the programmes and services delivered to children and youth with special needs and also in various professional development programmes. An example is the Tatari, Tautoko, Tauawhi tutor training programme. Each session began with a karakia and mihimihi before the whakapapa of the programme was given. The tutors were instructed using interactive techniques, practical demonstrations and experiential learning. Kaumatua were involved, and food was provided. Every session ended with a closing karakia. 
The inclusion of parents and whānau, the Māori community, Māori organisations and Māori workers Parents and whānau

Durie (1985, 1994), Pere (1991) and the Royal Commission on Social Policy (1988) all list whānaungatanga as a foundational component in their respective models of Māori Health, namely, Whare Tapa Wha, Te Wheke and Ngā Pou Mana.

... the family is the prime support system for Māori, providing care and nurturance, not only in physical terms but culturally and emotionally

(Durie, 1994, p. 73).

This view was widely accepted and practiced by many service providers. Parents and whānau, especially kaumatua, were consulted and involved in service provision including the development, adaptation and implementation of programmes, in identifying needs and in advertising services. Some whānau members were also involved as participants in disability-related research.

Whānau involvement was interpreted in its widest sense, for example in one organisation a Māori worker reported that where a single parent was flatting and did not have whānau support available, willing flatmates and friends were enlisted to take on the role of whānau. Collective responsibility was created by all adults receiving training, and getting involved in the programme to support the child.

\section{The Māori community and Māori organisations}

The Māori community and organisations were involved in a variety of ways but the most common strategy used consultation and involvement as outside resource and support people in the delivery of programmes and services. However, from the survey one worker sounded a warning:

The wrong people are sometimes involved. Who should be consulted depends on the point of the consultation. The Rūnanga and national boards serve the purpose of meeting Māori interests at an iwi and national level, but often closer flax roots consultation is needed to determine local needs.

\section{Māori workers}

Many participants noted that Māori children, youth and adults felt more comfortable with Māori than Pākehā workers. For example, an urban, Māori worker with over 20 years of experience said she found that Māori chose to use a particular service because they knew someone who worked there rather than because it was handy or based at a marae.

Māori are a dislocated people and so will go to people they know and feel comfortable with ..., even if they don't know the worker personally, they will feel more comfortable with a Māori because they can relate to them.

\section{Ready accessibility}

Many organisations went to considerable lengths to ensure Māori had ready access to their services. A wide range of strategies was used to ensure that child and parental involvement was not restricted by barriers such as inaccessible venues, unreasonable costs, lack of knowledge, inconvenient timing or inappropriate content. Asthma educators were particularly creative in this respect, advertising their services at marae functions, sporting and cultural events and popular locations such as shopping malls. As one woman from the survey explained:

I set my stall up outside McDonalds. I have a big bunch of coloured balloons that I give away. The kids see the balloons and drag their mothers over. It is amazing how many contacts I have made that way!

\section{Major challenges}

Data analysis revealed 39 different challenges faced by people and organisations that provided services and programmes for Māori learners with special needs. These were grouped into seven of the eight categories used for the positive strategies. ${ }^{2}$ Examples in each category illustrate their wide-ranging nature:

- Māori parents reluctant to participate, too shy to make their needs known or to complain about poor quality provisions

- Pākehā concepts of special needs used to identify Māori children

- high burnout and attrition rates of Māori workers with expertise

- organisations too small to provide a variety of programmes

- difficulty in translating national policy into practice at a local level resulting in policy tokenism

- a lack of coordination and liaison between organisations resulting in fragmented service provision and Māori "falling between the cracks"

- no wheelchair access on marae where services were being delivered.

Data analysis revealed the five most prevalent challenges in providing for Māori children and youth with special needs.

\section{Insufficient funding to provide the workforce and resources essential for adequate services and programmes}

Lack of funding was a major concern. It was seen as the main cause of understaffing.

In the mainstream services it is really about resourcing ... dotting one Māori person here and one group there, they can't realistically achieve anything. There is just not enough people for the workload.

Similarly, Māori programmes, services and resources were not being developed because of the expense involved. Even when they were developed, they were often not utilised

\footnotetext{
2 No example of the partnership category was found amongst the challenges people described.
} 
effectively because insufficient funding was provided to train people in their optimum use. One woman noted:

If programmes and resources are distributed in bits and pieces, you are doing a disservice to the programme, resource and research on which it is based but more importantly, you are doing a disservice to the students for whom they were intended.

Limited funding was cited as being a problem at both ends of the programme/resource development continuum. One person noted that any contracts she had been involved in did not allow sufficient money to do adequate market research to identify needs. The nature of the contract always assumed a certain need and did not allow for the validity or implications of this need to be investigated in any depth. Contract funding was seen to have other drawbacks apart from its limited amounts. In respect to service provision, some participants believed it contributed to job insecurity and a lack of commitment from both staff and "clients."

\section{Lack of culturally appropriate resources and people with the cultural and professional expertise needed to work with Māori children and youth with special needs}

This challenge went beyond the lack of funding to employ workers and provide resources. Even when sufficient money was available, the "right" people were often not available or the appropriate resources did not exist. The lack of Māori expertise was a particular problem for voluntary organisations. As one worker stated, "We are at the mercy of the people we attract and if we don't attract Māori we have no Māori expertise available."

Particular concern was expressed about the lack of culturally appropriate assessment measures and procedures. After describing the inappropriate questions asked in an assessment situation, one worker noted:
A lot of the resources that have been developed by Pākehā for Pākehā are not appropriate for Māori people. Do they have a choice if they want to be assessed in Māori? They don't and with the way children are coming through the system at the moment, bilingual and bicultural, these resources will be increasingly needed. There are not enough people developing culturally appropriate materials and measures. Even if it is not bilingual at least it should be Māori-appropriate.

\section{Lack of culturally appropriate, relevant training for staff in both mainstream and Māori services}

There was widespread concern about the dearth of training to prepare people to work effectively with Māori children and youth with special needs. One Māori worker commented:

Māori need more input; we need more health professionals within the system itself. More education is needed. There was such a huha about cultural safety in nursing training but once they have an understanding of what Māori really are about then all those defences just seem to melt away once they have a decent understanding of what actually is the problem. There should be ongoing education for all professionals, health, education, anything. There is a whole need for it. It is hard to change people's attitudes until they learn the facts and then they are fine. Social workers look into Treaty issues, history, Māori issues etc. and I have found them much better to work with than say, health professionals, so it has got a lot to do with their training. They have a better knowledge of things Māori and so are a lot better at addressing Māori issues.

Another worker stated that finding appropriate training was a real problem. She felt that there was a lack of respect and credibility for Māori workers in her organisation because they had no "officially recognised" qualifications. She set out to rectify this by undergoing training but found a lot of what was taught went against her Māori beliefs and values. For example, her training emphasised objectivity and neutrality which she felt went against a Māori way of working. A co-worker who enrolled for a different course was told, "We want you to feel you can bring your culture with you.' What did they think she could do, leave it behind?!"

One woman was an advocate for on-the-job training. She had often seen excellent programmes for Māori children collapse when a change of staff was involved. She suggested that the "old and new people" should work together for some time before the old person left the job. This not only gave the new person the opportunity to learn the routines and finer details of the programme but it also gave them time to establish their own mana and to "pick up the wairua" of the programme. Unfortunately, she noted that circumstances rarely permitted such a training and adjustment period.

The research data showed that successful training programmes for Māori workers often included one or more of the following components:

- the involvement of kaumatua, "because if you train a kuia you cater for the whole whānau .... You can cash in on their mana, influence, experience and spare time"

- iwi taking ownership of the training programme

- preliminary awareness sessions to get people interested and to alert them to the commitment required

- flexibility in content, style, delivery and timing, for example, provision for tangihanga attendance when necessary

- interactive, hands-on teaching processes involving group activities and allowing ample time for completion.

\section{Pākehā-centric attitudes towards special needs provision}

There were some respondents who did not value Māori services or recognise a need to consider Māori culture in service provision. Consequently, the development of culturally appropriate services was given a very low priority in their organisations. 
The tendency to disregard or undervalue Māori services was noted by a worker for a Māori organisation. She reported "wasting" a considerable amount of time trying to get mainstream services "on side." An example was given of a service that required doctors to refer patients to them. Despite spending a great deal of time visiting all the doctors in the region and explaining the service offered by the Māori organisation, only one referral had ever come from a doctor. Another Māori worker remarked:

You have got to go eighty percent of the way and that is trying. They meet you on their terms not yours. This is not always through arrogance but they are not sure of protocol so they withdraw from it. You become very sensitive about your credibility. Is it because we are Māori that they think like that? I could be doing some people a misjustice but you are never sure.

In many mainstream organisations, Māori workers were hired on a part time basis. One Māori worker felt that this signified a lack of commitment on the organisation's behalf. She explained that while there was plenty of work to be done, "it's as if meeting the cultural needs of Māori clients does not warrant full-time employment!"

Some respondents stated specifically that they did not think it was necessary to offer services or programmes for Māori with special needs because, "Māori needs are no different from anyone else's." While another typical comment was, "We just don't have the Māori clients to justify the expense involved in developing a programme for Māori."

\section{High stress levels of Māori staff working in the special needs area}

An issue of great concern was the high stress levels of many Māori working in the special needs area. This stress was caused by a multiplicity of factors but principal amongst them were unreasonable workloads and the tension between Māori and Pākehā "ways of working."

In many organisations, not only did Māori workers have high Māori "caseloads," but they were expected to be on call to provide training, guidance and Māori expertise to Pākehā colleagues when the need arose. While they applauded growing cultural awareness among Pākehā, this often came with the price tag of an increased workload for them. This was evident even in the voluntary sector and is illustrated in this story told by one survey Pākehā participant.

No, we haven't got anyone with Māori expertise in our organisation. We did have a Māori women join once. Her son had X. We were thrilled and asked her to join our executive. She only lasted one year, just stopped coming to our meetings. When she was approached to find out why, she said she had joined because her son needed help and that is all she wanted. She did not want to be the Māori expert for our organisation.

Workloads were just as high in Māori organisations where all workers had Māori expertise. While they might not have had responsibility for upskilling their workmates in Māori culture, they did have the previously mentioned burden of having to prove their credibility to many Pākehā workers and organisations.

Problems arising from different Māori and Pākehā "ways of working" were evident in both Māori and mainstream organisations. Māori workers reported taking a holistic, whānau-focused approach. However, the extra time needed to work in this way was usually not allowed for and required "outputs" could not be met. Working in this stressful situation often resulted in Māori workers becoming burnt out or leaving the service.

The reason why I left ... in the end was because I couldn't work in a Māori way although I did try ... I found working within their framework very restrictive. They couldn't understand that going to a kohanga and working with a bunch of kohanga people had more impact on what you were dealing with behaviour-wise than working one to one ... I had to fit in with their document, slotted into one of those boxes so they could say, "Yes, she is doing this," and when you are placed into a box you are restricted by words. There's no way I can be who I am ... The goal at the end is the same but how we get there is what is different. We do things differently. They have box, box, box and that is how you get there and then for us, these boxes, maybe they will go sideways and come back around here but the outcome is more effective doing it the way we do it.

\section{DISCUSSION AND CONCLUSION}

The organisation survey showed that a wide range of provisions existed for Māori children and youth with special needs. Fifty eight per cent of the organisations surveyed were providing programmes and services either especially developed or adapted for Māori. However, these programmes and services varied in their reported effectiveness and the degree of cultural input they contained.

On the positive side, 56 different strategies for providing for Māori children and youth with special needs were being utilized across a broad range of programmes and services. These strategies were culturally appropriate, empowering and resulted in successful service provision. On the negative side, 39 different barriers to culturally appropriate service provision were identified. Out of the organisations surveyed thirty-three percent reported doing nothing in particular for Māori children and youth and foty-one percent had no person with responsibility for or expertise in providing services or programmes for Māori with special needs. These are major causes for concern.

A number of the positive strategies identified are relatively simple to implement and could be employed by all organisations and individuals working in the special needs area. Others, are more involved and would require considerable planning, time, support and funding to achieve. Five improvements, in particular, are seen as vital. 
Firstly, there needs to be a substantial funding increase in this area to enable more staff to be employed and decrease the stress levels of those who are presently struggling. Increased funding would also support appropriate research and enable the development of Māori-relevant assessment measures, resources, programmes and services. It is envisaged that these new provisions would be broad-based, holistic in nature, accommodate Māori perceptions of special needs. They would incorporate Māori values, perspectives and ways of working, as well as take cognisance of the learner's home background, and involve and support their whānau. They would also be readily available in areas where Māori are presently under-serviced.

Secondly, bicultural training for all staff in both mainstream and Māori services should be developed. It is argued that preservice and in-service education should include a substantial, compulsory Māori component. Bicultural training would not only increase workers' cultural competence but, hopefully, it would also help to change those Pākehā-centric beliefs and attitudes which, at present, work against the accommodation and valuing of Māori concepts and ways of working. To bring about this attitudinal change, the bicultural curriculum would need to include a critical examination of majority cultural influence in education and society and an in-depth consideration of the causes, impact and maintenance of unequal power relationships, prejudice, racism, disabilism, social injustice, inequality and poverty. Along with compulsory bicultural training, measures should be introduced to increase special educational expertise among people involved in Māori organisations and Māori-medium education.

Thirdly, given that many Māori children, youth and adults feel more comfortable working with someone they can identify with and relate to culturally, there needs to be proactive recruitment, financial assistance, mentoring and support programmes to increase the number of Māori working in the special education/disability field. In addition, to address the present disadvantage experienced by Māori learners with special needs in Māori-medium education, emphasis should be placed on encouraging bilingual Māori to enter occupations that involve working with Māori learners with special needs. While a future increase in Māori personnel will be helpful in relieving the present work overload, it is vital that emotional and practical support be introduced immediately to reduce high stress levels, and to avoid burnout and further depletion of the existing Māori workforce.

Fourthly, parental and whānau involvement should be increased. Educational establishments and organisations that provide a welcoming, supportive environment will encourage involvement. In addition, the introduction of a range of financial, organisational and administrative arrangements to enable access may be required. Parents and whānau need opportunities to have a genuine say in the education and care of their children with special needs. Since raising these children usually involves extra work and stress for parents and whānau, it is essential that participation in any early childhood, school or organisational activity be an empowering, beneficial, supportive and enjoyable experience rather than an added burden.

Finally, Māori should be involved in all decision making affecting Māori learners with special needs at national, regional and organisational, levels and be empowered to provide their own iwi, hapū and pan-Māori services. This measure would not only assist in reducing the identified shortages in culturally effective provisions for Māori learners with special needs but it would also help to lessen the general power imbalance in educational decision making that presently exists in Aotearoa/New Zealand. In order for Treaty of Waitangi obligations to be met, Māori need to be given the power and resources to determine their own future. This applies to all facets of life including the provision of programmes and services for Māori learners with special needs. If there is any field in which diversity in all its forms should be recognised, accommodated and valued, surely it is in special education!

\section{REFERENCES}

Bevan-Brown, J. (2002). Culturally appropriate, effective provision for Māori learners with special needs: He waka tino whakarawea. PhD Thesis, Massey University, Palmerston North.

Bevan-Brown, J., \& Bevan-Brown, W. (1999). SE2000: Kura kaupapa Māori report: Phase One. Report to the Ministry of Education. Palmerston North: Massey University.

Cullen, J., \& Bevan-Brown, J. (1999). Resourcing special education in early childhood: Database and best practice validation. Final report to the Ministry of Education. Palmerston North: Massey University, Institute for Professional Development and Educational Research.

Duckworth, S. (1999). Waikato behavioural prototype The evaluation. Proceedings of the Special Education 2000 Research Conference, Auckland, New Zealand. Wellington: Ministry of Education.

Durie, M. H. (1985). A Māori perspective of health. Journal of Social Sciences and Medicine, 20 (5), 483-6.

Durie, M. H. (1994). Whaiora Māori health development. Auckland: Oxford University Press.

Massey University Research Team. (1999). Special Education 2000: Monitoring and evaluation of the policy. Phase One Final Report. Palmerston North: Massey University College of Education.

Massey University Research Team. (2001). Special education 2000: Monitoring and evaluation of the policy. Phase Two Final Report. Palmerston North: Massey University College of Education.

Massey University Research Team. (2002). Special education 2000. Monitoring and evaluation of the policy. Final Report. Palmerston North: Massey University College of Education. 
Ministry of Health. (2001). A brief summary of the analysis of submissions to the New Zealand disability strategy discussion document, Making a World of Difference: Whakanui Oranga. Wellington: Author.

Pere, R. (1991). Te wheke: A celebration of infinite wisdom. Gisborne: Ao Ako Global Learning New Zealand.

Peretini, A., Thomas, D., Kingi, S., Coffey, B., Philips, J., \& Wearing, D. (2000). Cultural audit of Specialist Education Services, final report. Wellington: Specialist Education Services.

Royal Commission on Social Policy (1988). The April Report: Report of the Royal Commission on Social Policy. (Vols 2,3 (2) \& 4). Wellington: Author.

Schwarz, I., \& Gillon, G. (1999). A review of best practices and service needs in speech language therapy - Results of Special Education 2000 speech-language initiative research projects. Proceedings of the Special Education 2000 Research Conference, Auckland, New Zealand. Wellington: Author.

TAKOA 1996. Te aka kumara o Aotearoa: Directory of Māori organisations and resource people in Aotearoa. Auckland: Tuhi2 Communications.

Wilkie, M. (1999). Special Education 2000: So - What's so special about special education for Māori? Wellington: New Zealand Council for Educational Research.

Wilkie, M. (with Berryman, M., Himona, T., \& Paul, T.) (2001). Matauranga motuhake. Wellington: New Zealand Council for Educational Research.

Wylie, C. (2000). Picking up the pieces. Review of Special Education 2000. He tataritanga mo te Matauranga Motuhake 2000. Wellington: Ministry of Education.

\section{PROFILE OF AUTHOR}

Jill Bevan-Brown is a senior lecturer in the Department of Learning and Teaching at Massey University. She is coordinator of the Batchelor of Education, Special Education. Jill's $30+$ years in education has involved teaching at all levels from early childhood to tertiary and has included service as a GLU teacher, in a special class, adjustment class, accelerate class and at Otaki Health Camp. Having Māori heritage, Jill has a particular interest in Māori learners with special needs and has researched extensively in this area.

Contact at : J.M. Bevan-Brown@massey.ac.nz 